\title{
연안활동장소의 위험도 평가체계 수립 연구 A Study on Evaluation System of Risk Assessment at Coastal Activity Areas
}

\author{
박선중* . 박설화** . 서희정*** . 박승민 $* * * *$ \\ Seon Jung Park*, Seol Hwa Park**, Heui Jung Seo*** and Seung Min Park****
}

\begin{abstract}
요 지 : 연안안전사고는 인적과실이 차지하는 비율이 매우 높고 같은 요인에 의한 사고가 반복적으로 발생하는 특 징이 나타나고 있다. 이들 장소를 중심으로 관리기관에서는 사고 예방을 위한 각종 대비책을 마련하여 시행하고 있으 나 제한된 예산에 따른 안전시설물 및 안전관리 인력의 부족과 기상청 기상특보에 의존하고 있는 연안안전사고 위험 예보제 운용체계의 한계 등으로 선제적 -ㅡㅡㅇ동적 대응력이 많이 떨어지는 것이 현실이다. 본 연구에서는 연안안전사고 발생 이후의 수습 중심 안전관리체계에서 안전사고 발생 이전에 사고 유발요소의 관리와 위험도 예측.평가, 사고발생 이후의 대응 및 경감대책을 시행할 수 있는 선제적, 능동적 연안안전 관리체계 구축기반 마련의 일환으로 연안활동장 소의 위험도 평가체계를 수립.제안하였다. 2017년 이후의 연안안전사고 현황 분석을 통해 연안활동장소별 안전사고를 유발하는 주요 위험요인을 식별하였으며, 이를 기반으로 위험도 평가를 위한 주요 평가인자 및 지표를 설정하였다. 제안된 위험도 평가 방법론은 해양경찰청에서 지정·관리되고 있는 주요 40 개 위험구역을 대상으로 적용하였다.
\end{abstract}

핵심용어 : 연안활동장소, 연안안전사고, 위험구역, 위험도 평가

\begin{abstract}
Coastal safety accidents are characterized by a high proportion of human negligence and repeated occurrences of accidents caused by the same factors. The Korea Coast Guard prepares and implements various countermeasures to prevent accidents at coastal safety accident sites. However, there is a shortage of safety facilities and safety management personnel according to the limited budget. In addition, the ability to be proactively and proactively respond is low due to the limitations of the coastal safety accident risk forecasting system, which relies on the meteorological warning of the Korea Meteorological Administration. In this study, as part of preparing the foundation for establishing a preemptive and active coastal safety management system that can manage accident-causing factors, predict and evaluate risk, and implement response and mitigation measures after an accident occurs before coastal safety accidents occur. The establishment of a risk assessment system was proposed. The main evaluation factors and indicators for risk assessment were established through the analysis of the status of coastal safety accidents. The risk assessment methodology was applied to 40 major hazardous areas designated and managed by the Korea Coast Guard.
\end{abstract}

Keywords : coastal activity areas, coastal safety accident, hazard area, risk assessment

\section{1. 서 론}

국토의 삼면이 바다인 우리나라는 연안역을 중심으로 다양 한 관광자원들이 분포하고 있으며, 국민소득의 향상으로 인 한 생활수준 변화 및 여가시간 증대로 바닷가, 갯벌 등 연안 을 중심으로 관광, 해양스포츠 등의 여가활동 수요가 증대되 고 있다(Song, 2019). 최근 들어 태풍, 이상파랑 등 연안사고 위험성을 증대시키는 해양외력의 강도와 발생빈도의 증가, 연 안사고 위험에 노출되는 활동인구가 증가함에 따라 연안활동 장소에서의 안전사고 노출 위험도는 더욱 높아지고 있다.
안전에 대한 국민의 인식 변화와 함께 실효성 있는 연안안 전관리 방안 마련을 위한 관리.감독기관의 관심과 노력은 꾸 준히 증대되고 있으나 아직까지 안전사고 방지를 위한 대책 은 안전사고의 증가속도에 적절하게 대응하지 못하고 있는 실 정이다. 연안사고 예방에 관한 법률(법률 제17049호) 및 연 안사고 안전관리규정(해양경찰청훈령 제 170 호)에서는 연안활 동장소에 대한 위험도평가 실시를 의무화하고 있으며, 해양 경찰청에서는 연안해역내 위험구역 관리 및 반복·지속적으로 발생하는 안전사고를 저감시키기 위하여 2020년 11월 연안 사고 안전관리규정(해양경찰청훈령 제 197 호)의 일부개정을 통

\footnotetext{
*(주)혜인이엔씨 기술연구소 이사 (Corresponding author: Seon Jung Park, Director, Hyein E\&C Technical Research Institute, WoolimBlue9BizCenter A-dong 24F, 583 Yangcheon-ro, Gangseo-gu, Seoul 07547, Korea, Tel: +82-2-2093-2342, Fax: +82-2-2093-2209, nayana_sj@hanmail.net) **(주)혜인이엔씨 기술연구소 차장(Deputy General Manager, Hyein E\&C Technical Research Institute)

***(주)혜인이엔씨 기술연구소 이사(Director, Hyein E\&C Technical Research Institute)

****(주)혜인이엔씨 기술연구소 부장(General Manager, Hyein E\&C Technical Research Institute)
} 
해 위험구역 평가 기준 변경 및 정량적 지표를 활용한 위험 등급 평가 방안을 마련하는 등 연안사고 예방을 위한 법률적 기반을 재정비한 바 있으며, 2021년 5월 기준 848개소의 위 험구역이 지정·관리되고 있다. 그러나 위험등급 평가지표가 주 관적 경향이 강한 특성상 평가결과를 국민의 안전한 연안활 동 지원에 활용하는데 한계가 있으며, 이에 따라 국민의 안 전한 연안활동 지원 및 안전사고 예방을 위하여 연안활동장 소의 위험도를 평가할 수 있는 보다 효율적인 평가체계 마련 이 필요한 상황이다.

본 연구에서는 연안안전사고 발생 이후의 수습 중심 안전 관리체계에서 안전사고 발생 이전에 사고 유발요소의 관리와 위험도 예측.평가, 사고발생 이후의 대응 및 경감대책을 시 행할 수 있는 선제적-능동적 연안안전 관리체계 구축기반 마 련의 일환으로 연안안전 위험도 평가를 위한 위험성 평가지 표 설정 및 평가 방법론을 제안하고, 해양경찰청에서 지정. 관리되고 있는 주요 위험구역 40 개소를 대상으로 적용하였다.

\section{2. 위험도 평가 사례 분석}

\section{1 국내 사례}

국내 연안활동장소를 대상으로 종합적 위험성 평가방안을 제시한 연구는 2016년 이후 본격적으로 시작되었다. MPSS (2016)에서는 시·군·구별로 연안 안전사고 예방·대응을 위한 연안안전지표 항목을 객관적으로 평가하여 수치화한 연안안 전지수 활용방안을 제안하고, 평가대상 지자체 및 시설물이 있는 구역을 설정하여 표본 조사 방법, 현장조사 및 연안안 전지수 평가 방법, 평가추진체계, 결과 공표 및 사후관리 방 법 등을 제시하였으며, 연안안전지수 도입을 위한 연안관리 법 개정안을 제안하였다. 안전지수 산출을 위해 지역적 요인, 인적·사고이력 요인, 예방 요인으로 평가지표를 구성하였으며, 지표간 가중치 결정을 위해 계층구조분석(Analytic Hierarchy Process: AHP) 기법을 적용하였다.

Ministry of Ocean and Fisheries(2017, 2019)에서는 지자 체별로 집계된 연안안전 사고 건수로 평가되는 사고지표, 조 사 대상 지역에 설치된 안전시설물의 설치 적정성과 유지보 수 상태에 따라 평가되는 시설지표, 평가대상 시·군·구 기초 자치단체의 연안안전 관리 능력을 측정한 관리·운영지표를 조 합한 연안안전지수를 제안하였다.

Korea Coast Guard(2018)에서는 정량적으로 평가할 기준 이 없는 현 법령의 위험도 평가를 보완하기 위하여 국내·외 의 연안 안전·위험도 평가 방법들을 검토하고 동·서해안 사 전 현장 조사를 통해 평가 지표별 정량화 방법을 제안하였다. 사고가 발생되는 장소(갯벌, 갯바위, 방파제, 선착장)별로 주 요 사고 발생 유형과 유발요소를 토대로 안전·위험도를 계량화 할 수 있는 평가 방법을 제시하고 향후 개발될 연안 안전·위 험도 지수의 명칭으로 ‘연안활동위험지수’ 제안한 바 있다.

국립해양조사원에서는 연안재해취약성 평가체계 수립 용역
을 통해 2020년까지 연안역을 포함하는 54개 시군, 총 9,649.3 $\mathrm{km}$ 해안선을 대상으로 연안역에서 발생하는 재해에 대한 연 안역의 노출, 민감도, 적응능력의 취약정도를 정량적으로 평 가하였다. 연안재해취약성평가체계는 국내에 최초로 도입인 연안재해평가 기준인 동시에 전 연안에 적용된 시스템으로, 연안의 종합계획 수립을 위한 기초자료 제공을 주요 목적으 로 하고 있다. 국소적인 지역을 대상으로 지정·관리되고 있 는 위험구역의 위험도 평가에는 낮은 해상도로 정확성이 결 여될 뿐 아니라 안전사고의 예방과 관리 목적에도 부합하지 않은 것으로 판단된다.

실시간 예보정보 산출 관련으로는 국립해양조사원의 해양 예보정보가 있다. 이는 안전한 해양체험 활동을 지원하기 위 하여 해양, 기상정보를 융합하여 국내 주요 해양레저활동 장 소를 대상으로 바다낚시, 해수욕, 갯벌체험 등의 체감 정도를 좋음, 나쁨 등 5 단계로 알기 쉽게 지수화 한 해양예보정보를 제공하는 서비스이다.

Lee et al.(2020)은 연안활동이 이루어지는 장소와 사고유 형에 따른 위험평가 지표를 기반으로 위험지수를 개발하였다. 위험지수를 평가하기 위한 평가요소로는 환경적 요인과 사회. 경제적 요인으로 구분하였고, 평가지표로 기상조건, 해상조건, 지형조건, 활동구역 및 이용자의 특성 등 22 개의 지표를 활 용하는 방안을 제안하였다.

행정안전부는 안전사고 사망자 감축 노력의 일환으로 교통 사고, 화재, 범죄, 생활안전, 자살, 감염병 등 6 개 분야별 전 국 지방자치단체의 안전수준을 매년 평가하고, 재난 및 안전 관리 기본법 제 66 조의 10 (안전지수의 공표)에 따라 지역안전 등급을 공개하고 있다.

제도적 관점에서는 $\operatorname{Kim}(2019)$ 은 현행 연안해역 안전관리 제도의 내용을 살펴보고, 그간 제기되었던 문제점과 개선방 안을 법제도적 관점과 실무적 관점으로 나누어 제시하였으며, 아울러 우리나라 법체계 전체의 관점에서 해양사고의 효율적 관리를 위한 보완 점검의 필요성을 제기한 바 있다. Song (2019)은 국내 연안사고 안전관리 문제점을 도출한 후 이에 대한 개선방안을 제시하는 것을 목적으로, 전국 연안을 5 개 권역으로 분류하여 연안 안전사고 발생 현황을 조사하였으며, 문헌 및 실무자 면담조사를 통해 연안 사고 안전관리 문제점 을 도출한 후 개선방안을 제시하였다.

\section{2 국외 사례}

Satta et al.(2015)은 지중해 지역의 기후변화 위험이 사회 경제문제와 깊은 관련이 있다는 인식하에 지중해 연안위험지 수(Coastal Risk Index for the Mediterranean, CRI-MED) 를 개발하였다. CRI-MED는 기후변화에 관한 정부 간 협의 체(Intergovernmental Panel on Climate Change, IPCC)의 접근법과 위험에 주목하면서 통합하여 개발한 지수로서 지중 해 연안의 기후변화와 관련된 위험을 평가하는데 이용되고 있다. 
호주의 경우 해변안전관리 프로그램(Australian Beach Safety and Management Program, ABSAMP)을 통해 주요 해변의 공공안전 위험 평가를 실시하고 있다. 이 프로그램은 시드니 대학의 Andrew Short 교수가 Surf Life Saving Australia와 함께 개발한 것으로 해변 이용객에게 영향을 미치는 자연적, 지형적 요인 등을 식별하여 위험성을 평가하는 방식으로 해 변의 위험성을 4등급으로 구분하여 평가하고 있다(Tweed Shire Council , 2018). 특히, 해변 안전을 개선하고 인명 구 조 자원을 보다 효율적으로 관리하기 위하여 해변 안전 및 관 리 데이터베이스 프로그램(Australian Beach Safety and Management Database Program)도 함께 운영하고 있다. 해
당 데이터베이스에는 호주 전역의 11,000 개 이상의 해변을 대 상으로 지리적·물리적 정보를 포함하고 있다. 주요 데이터로 는 해변 위치, 구역 지정, 해변 유형 및 등급, 도로, 지형특 징 등 다양한 정보를 포함하고 있다.

영국에서는 왕립구명정기구(Royal National Lifeboat Institute, $\mathrm{RNLI}$ )와 플리머스대학의 협업을 통해 해변위험도 평가방법 을 개발하였다. 해당 방법은 호주의 ABSAMP를 영국해변 사 정에 맞게 수정한 것으로 해양 에너지와 인구 2 개 지표에 각 각 2 개 인자를 두고 이들의 등급 산정 결과를 합산하여 낚 시, 서핑, 패들링, 수영 등 해양 레저활동이 주로 이뤄지는 해 변과 사구, 쇄파대 및 서프존(surf zone), 서프존을 넘는 곳

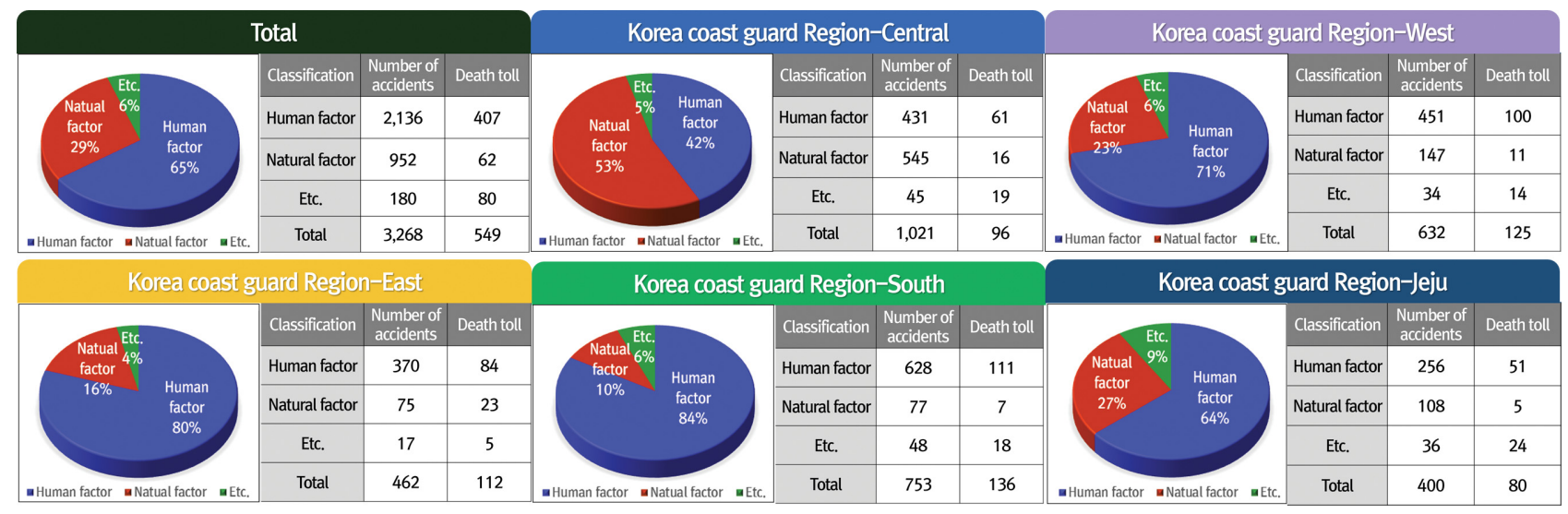

Fig. 1. Trends of safety accident (2017.01 2020.12).

Table 1. Status of safety accident (2017 2020)

\begin{tabular}{|c|c|c|c|c|c|c|}
\hline & \multirow{2}{*}{ Classification } & \multicolumn{2}{|c|}{ Safety accident } & \multicolumn{2}{|c|}{ Mortality accident } & \multirow{2}{*}{ death rate $(\%)$} \\
\hline & & number of accidents & rate $(\%)$ & death toll & rate $(\%)$ & \\
\hline & Total & 3,268 & - & 549 & - & 16.8 \\
\hline \multirow{9}{*}{$\begin{array}{l}\text { human } \\
\text { factor }\end{array}$} & Subtotal & 2,136 & 65.4 & 407 & 74.1 & 19.1 \\
\hline & safety violation & 19 & 0.9 & 3 & 0.7 & 15.8 \\
\hline & lack of swimming skills & 185 & 8.7 & 33 & 8.1 & 17.8 \\
\hline & drinking & 484 & 22.7 & 67 & 16.5 & 13.8 \\
\hline & disease & 42 & 2.0 & 18 & 4.4 & 42.9 \\
\hline & suicide, suicide attempt, self-injury & 276 & 12.9 & 85 & 20.9 & 30.8 \\
\hline & careless driving & 201 & 9.4 & 50 & 12.3 & 24.9 \\
\hline & disorientation & 44 & 2.1 & 4 & 1.0 & 9.1 \\
\hline & carelessness & 885 & 41.4 & 147 & 36.1 & 16.6 \\
\hline \multirow{5}{*}{$\begin{array}{l}\text { natural } \\
\text { factor }\end{array}$} & Subtotal & 952 & 29.1 & 62 & 11.3 & 6.5 \\
\hline & bad weather & 102 & 10.7 & 4 & 6.5 & 3.9 \\
\hline & tide unawareness & 667 & 70.1 & 16 & 25.8 & 2.4 \\
\hline & tidal current unawareness & 52 & 5.5 & 5 & 8.1 & 9.6 \\
\hline & wave & 131 & 13.8 & 37 & 59.7 & 28.2 \\
\hline \multirow{4}{*}{ etc. } & Subtotal & 180 & 5.5 & 80 & 14.6 & 44.4 \\
\hline & offshore coastal structures and obstacles & 25 & 13.9 & 1 & 1.3 & 4.0 \\
\hline & ship·leisure equipment failure & 18 & 10.0 & 1 & 1.3 & 5.6 \\
\hline & etc. (unexplained accident) & 137 & 76.1 & 78 & 97.5 & 56.9 \\
\hline
\end{tabular}


등 세 가지 활동장소를 대상으로 5 개 등급으로 구분된 위험 잠재성을 평가하는 방법이다.

Carvalho and Woodroffe(2019)는 호주 뉴사우스웨일스 남 부에 위치한 일라와라 해안의 갯바위를 대상으로 개방된 해 안에서 높은 파도에 노출된 환경의 형태학적(평균고도, 방향, 조성형태 등) 평가를 통해 위험지수를 산정하는 방안을 연구 하였다.

\section{3. 연안안전사고 위험요인 식별}

\section{1 연안안전사고 특성}

2017년에서 2020년까지 발생한 국내 연안사고는 총 3,268
건이며, 이 중 사망자 수는 549명으로 발생건수 대비 사망률 이 약 $16.8 \%$ 에 달하고 있다. 이 중 중부지방해양경찰청(인천, 경기, 충남) 관할에서는 전체 사고의 $31.2 \%(1,021$ 건)로 가장 많은 사고가 발생되었으며, 사망자 수 기준에서는 남해지방 해양경찰청(부산, 울산, 경남) 관할이 $24.8 \%$ 인 136 명이 발생 한 것으로 조사되었다(Fig. 1). 안전사고 요인은 인적요인에 의한 사고가 전체 사고의 $65.4 \%$ 인 2,136 건으로 가장 높은 비 중을 차지하며, 전체 사망자 또한 $74.1 \%(407$ 명 $)$ 를 차지하고 있다(Table 1). 인적요인에 의한 안전사고 중 $41.4 \%$ 인 885 건 이 연안활동자의 부주의로 인해 발생되었으며, 사망사고의 경 우 개인 부주의에 의한 사고와 자살 사고가 상당부분을 차지 하고 있다(Table 2), 특히 코로나바이러스(COVID-19) 확산에

Table 2. Status of safety accident by region (2017 2020)

\begin{tabular}{|c|c|c|c|c|c|c|c|c|c|}
\hline \multirow[b]{2}{*}{ Classification } & \multicolumn{3}{|c|}{ human factor } & \multicolumn{3}{|c|}{ natural factor } & \multicolumn{3}{|c|}{ etc. } \\
\hline & $\begin{array}{l}\text { number of } \\
\text { accidents }\end{array}$ & death toll & $\begin{array}{c}\text { death } \\
\text { rate }(\%)\end{array}$ & $\begin{array}{c}\text { number of } \\
\text { accidents }\end{array}$ & death toll & $\begin{array}{c}\text { death } \\
\text { rate }(\%)\end{array}$ & $\begin{array}{l}\text { number of } \\
\text { accidents }\end{array}$ & death toll & $\begin{array}{c}\text { death } \\
\text { rate }(\%)\end{array}$ \\
\hline Total & 2,136 & 407 & 19.1 & 952 & 62 & 6.5 & 180 & 80 & 44.4 \\
\hline Central & $431(20.2)$ & $61(15.0)$ & 14.2 & $545(57.2)$ & $16(25.8)$ & 2.9 & $45(25.0)$ & $19(23.8)$ & 42.2 \\
\hline West & $451(21.1)$ & $100(24.6)$ & 22.2 & $147(15.4)$ & $11(17.7)$ & 7.5 & 34 (18.9) & 14 (17.5) & 41.2 \\
\hline East & $370(17.3)$ & $84(20.6)$ & 22.7 & $75(7.9)$ & $23(37.1)$ & 30.7 & $17(9.4)$ & $5(6.3)$ & 29.4 \\
\hline South & $628(29.4)$ & 111 (27.3) & 17.7 & 77 (8.1) & $7(11.3)$ & 9.1 & 48 (26.7) & $18(22.5)$ & 37.5 \\
\hline Jeju & $256(12.0)$ & $51(12.5)$ & 19.9 & 108 (11.3) & $5(8.1)$ & 4.6 & $36(20.0)$ & $24(30.0)$ & 66.7 \\
\hline
\end{tabular}

(): Ratio of number of accidents and death toll against the total by factor (\%)

Table 3. Types of safety accident

\begin{tabular}{|c|c|c|c|c|c|}
\hline & \multirow{2}{*}{ Classification } & \multicolumn{4}{|c|}{ number of safety accidents and accident rate (\%) } \\
\hline & & 2017 & 2018 & 2019 & 2020 \\
\hline \multicolumn{2}{|r|}{ Total } & 693 & 753 & 936 & 886 \\
\hline \multirow{11}{*}{ submersion } & & $377(54.4)$ & $434(57.6)$ & $534(57.1)$ & $519(58.6)$ \\
\hline & surface type & $91(13.1)$ & $113(15.0)$ & $79(8.4)$ & $69(7.8)$ \\
\hline & leisure submersion & $85(12.3)$ & $90(12.0)$ & $68(7.3)$ & $52(5.9)$ \\
\hline & industrial submersion & $6(0.9)$ & $23(3.1)$ & $11(1.2)$ & $17(1.9)$ \\
\hline & underwater type & $40(5.8)$ & $40(5.3)$ & $36(3.8)$ & $43(4.9)$ \\
\hline & leisure submersion & $17(2.5)$ & $19(2.5)$ & $19(2.0)$ & $23(2.6)$ \\
\hline & industrial submersion & $23(3.3)$ & $21(2.8)$ & $17(1.8)$ & $20(2.3)$ \\
\hline & general type & $246(35.5)$ & $281(37.3)$ & $419(44.8)$ & 407 (45.9) \\
\hline & falling submersion & $184(26.6)$ & $203(27.0)$ & $237(25.3)$ & $179(20.2)$ \\
\hline & isolated submersion & $11(1.6)$ & $8(1.1)$ & $8(0.9)$ & $12(1.4)$ \\
\hline & other submersion & $51(7.4)$ & $70(9.3)$ & $174(18.6)$ & $216(24.4)$ \\
\hline \multirow{7}{*}{$\begin{array}{c}\text { non- } \\
\text { submersion }\end{array}$} & & $316(45.6)$ & $319(42.4)$ & $402(42.9)$ & $367(41.4)$ \\
\hline & surface & $37(5.3)$ & $52(6.9)$ & $48(5.1)$ & $35(4.0)$ \\
\hline & drift & $37(5.3)$ & $52(6.9)$ & $48(5.1)$ & $35(4.0)$ \\
\hline & general type & $279(40.3)$ & $267(35.5)$ & $354(37.8)$ & $332(37.5)$ \\
\hline & falling & $83(12.0)$ & $69(9.2)$ & $87(9.3)$ & $78(8.8)$ \\
\hline & isolation & $183(26.4)$ & $181(24.0)$ & $232(24.8)$ & $225(25.4)$ \\
\hline & etc. & $13(1.9)$ & $17(2.3)$ & $35(3.7)$ & $29(3.3)$ \\
\hline
\end{tabular}

(): Ratio of number of accidents against the total (\%) 
Table 4. Cause classification of safety accident by region (2017 2020)

\begin{tabular}{|c|c|c|c|c|c|c|}
\hline & Classification & Central & West & East & South & Jeju \\
\hline & Total & 1,021 & 632 & 462 & 753 & 400 \\
\hline \multirow{9}{*}{$\begin{array}{l}\text { human } \\
\text { factor }\end{array}$} & Subtotal & $431(42.2)$ & $451(71.4)$ & $370(80.1)$ & $628(83.4)$ & $256(64.0)$ \\
\hline & safety violation & 0 & 1 & 10 & 0 & 8 \\
\hline & lack of swimming skills & 51 & 20 & 46 & 29 & 39 \\
\hline & drinking & 93 & 84 & 99 & 162 & 46 \\
\hline & disease & 7 & 2 & 7 & 11 & 15 \\
\hline & suicide, suicide attempt, self-injury & 62 & 55 & 23 & 116 & 20 \\
\hline & careless driving & 32 & 83 & 13 & 55 & 18 \\
\hline & disorientation & 33 & 10 & 0 & 0 & 1 \\
\hline & carelessness & 153 & 196 & 172 & 255 & 109 \\
\hline \multirow{5}{*}{$\begin{array}{l}\text { natural } \\
\text { factor }\end{array}$} & Subtotal & $545(53.4)$ & $147(23.3)$ & $75(16.2)$ & $77(10.2)$ & $108(27.0)$ \\
\hline & bad weather & 29 & 7 & 15 & 17 & 34 \\
\hline & tide unawareness & 478 & 118 & & 26 & 45 \\
\hline & tidal current unawareness & 20 & 10 & 9 & 3 & 10 \\
\hline & wave & 18 & 12 & 51 & 31 & 19 \\
\hline \multirow{4}{*}{ etc. } & Subtotal & $45(4.4)$ & $34(5.4)$ & $17(3.7)$ & $48(6.4)$ & $36(9.0)$ \\
\hline & offshore coastal structures and obstacles & 8 & 4 & 5 & 6 & 2 \\
\hline & ship leisure equipment failure & 7 & 3 & & 5 & 3 \\
\hline & etc. (unexplained accident) & 30 & 27 & 12 & 37 & 31 \\
\hline
\end{tabular}

(): Ratio of number of accidents against the total by Coast Guard (\%)

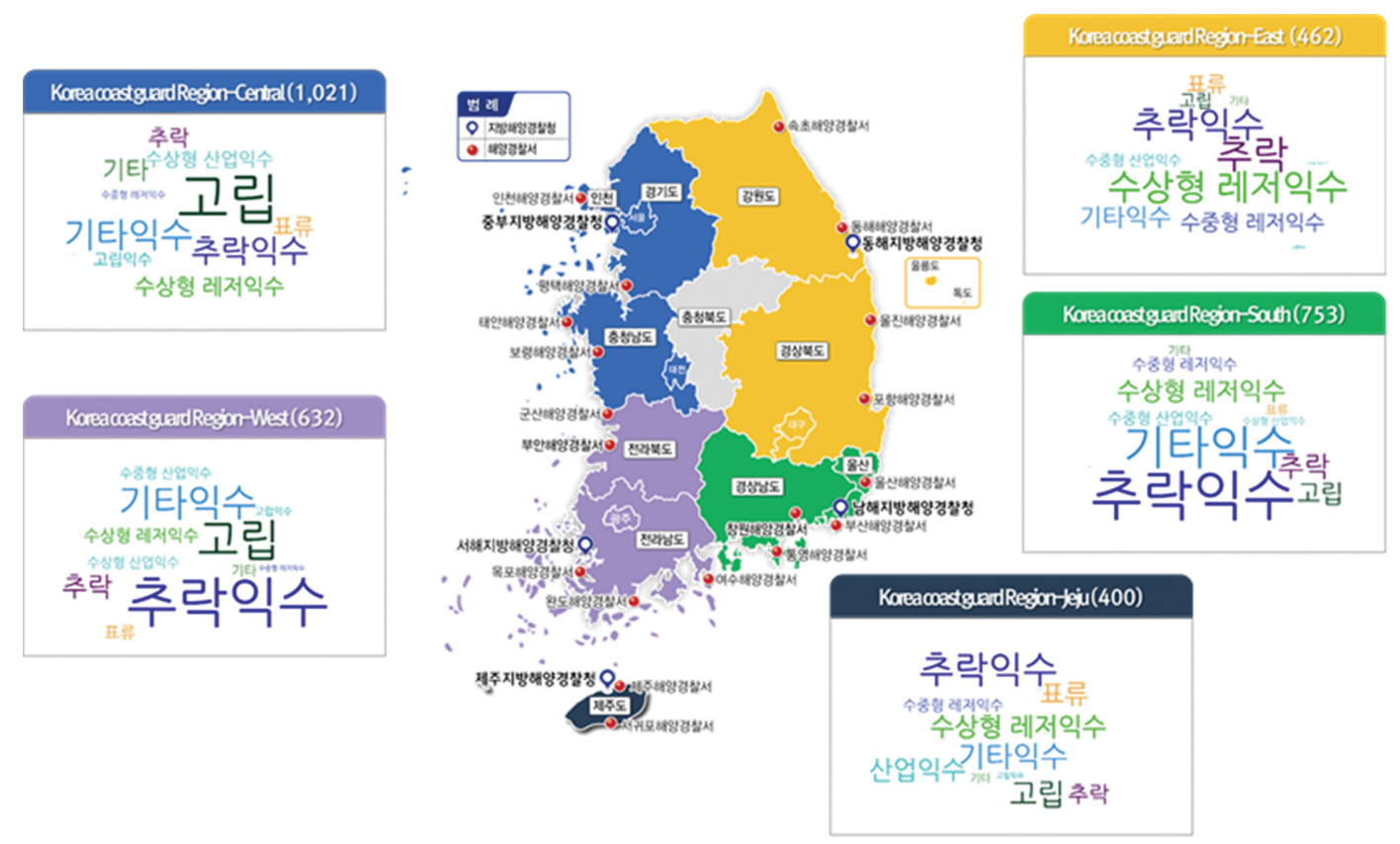

Fig. 2. Types of safety accident.

따른 외부활동 인구의 감소에도 불구하고 연안사고 발생건수 는 2019년 936건, 2020년 886건으로 크게 감소하지는 않은 것으로 나타났다.

연안안전사고는 지역별 연안활동 유형에 따라 사고 다발장 소에 유형 차이는 있으나, 주로 항포구, 갯바위, 해안가 등의
장소에서 가장 빈번하게 발생하고 있다. 연안안전사고를 유 형별로 구분하면, 고립사고(821건, $25.1 \%$ ), 추락익수사고(803 건, 24.6\%)가 가장 빈번하게 발생하고 있다(Table 3). 중부청 은 고립사고가 가장 높은 비중을 차지하며, 서해청과 남해청, 제주청에서는 추락익수사고, 동해청은 추락으로 인한 안전사 
고가 가장 많이 발생하고 있다(Table 4, Fig. 2). 여가활동이 많아지는 주말(토.일요일)에 많은 사고의 발생되며, 연안활동 이 활발해지는 오후(13 16시) 시간대에 집중되는 것으로 나 타났다.

\section{2 연안활동장소 위험요인 식별}

연안활동장소에 대한 위험성 평가시 활용될 수 있는 평가 지표 및 인자를 도출하기 위하여 해양경찰청에서 제공된 2017 년 이후 연안사고 통계자료를 사고 장소, 요인, 유형별로 분 류하여 직접적인 사고 원인을 분석하였다. 안전사고의 발생 은 단순요인에 의해 발생한 경우가 많으나 정적, 동적 요인 들의 복합적인 상호작용에 의한 사고도 많이 발생하고 있다. 사고요인 중 안전 미준수, 음주, 수영 미숙 등 연안활동자의 부주의에 의한 사고가 가장 높은 비중을 차지하며, 조석 미
인지, 해무 등 해양외력 및 기상여건이 직접적인 사고요인으 로 작용한 경우는 중부지방해양경찰청 관할구역을 제외하고 크게 영향을 미치지 않는 것으로 분석되었다. 특히, 인적과실 이 차지하는 비율이 매우 높아 같은 요인에 의한 사고가 반 복적으로 발생하는 특징이 나타내고 있다.

지방청별 사고 장소, 유형, 요인에 대해 종합적으로 살펴보 면, 중부청(인천, 경기도, 충청남도) 관할구역의 경우, 갯바위, 갯벌 구역에서 고립에 의한 사고가 주된 사고 유형으로 분석 되었으며, 서해청(전라남도, 전라북도) 관할구역은 항포구, 해 안가 구역에서 추락에 의한 사고가 주된 사고 유형인 것으로 나타났다. 동해청(강원도, 경상북도) 관할구역의 경우, 해안가, 방파제(테트라포트) 구역에서 추락, 익수에 의한 사고가 주된 사고 유형으로 분석되었고, 남해청(부산, 울산, 경상남도) 관 할구역은 항포구, 해안가에서 추락에 의한 사고가 주된 사고
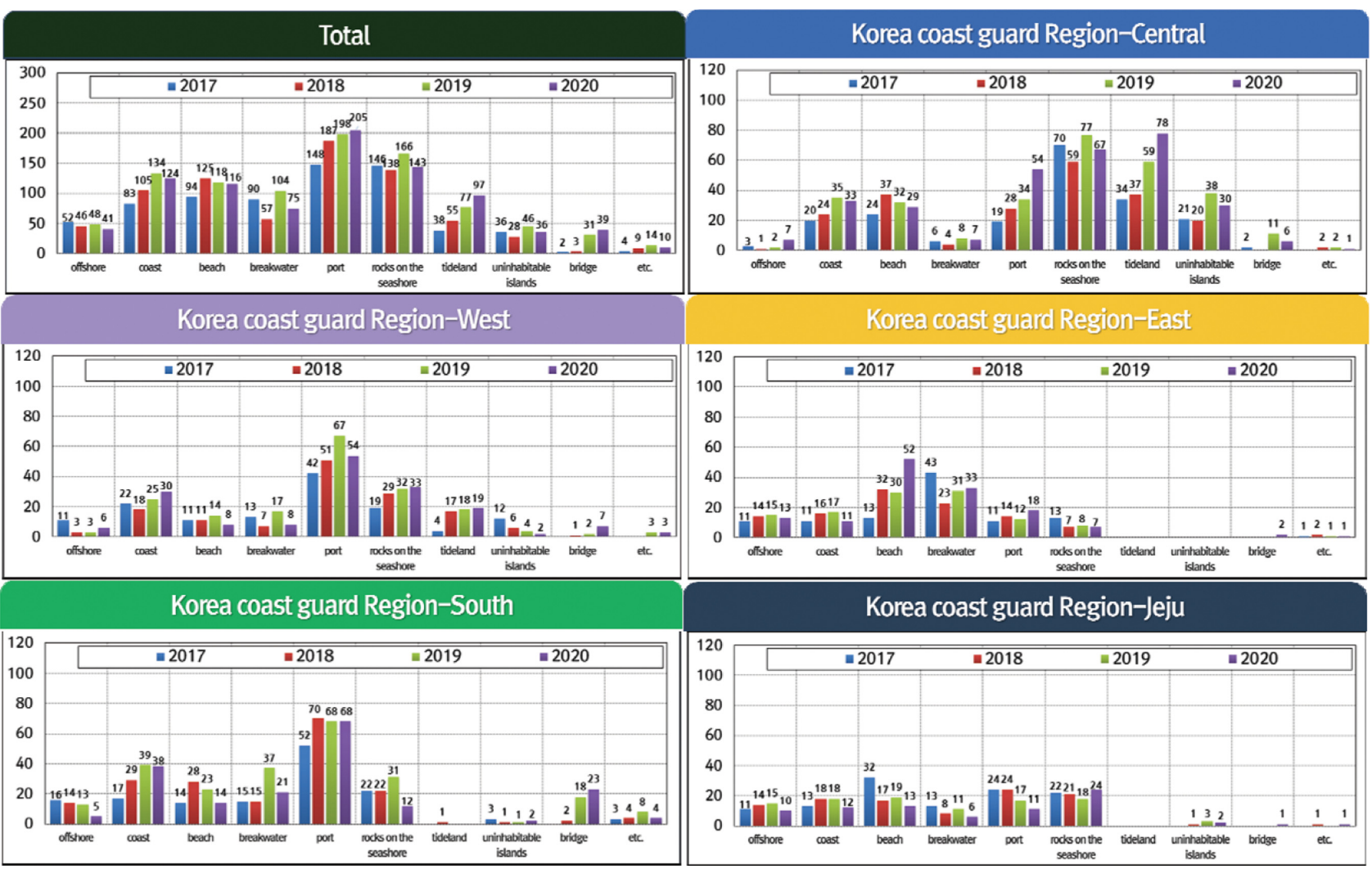

Fig. 3. State of safety accident by place.

Table 5. State of safety accident by place

\begin{tabular}{ccccccccccccc}
\hline \hline \multirow{2}{*}{ Classification } & \multicolumn{7}{c}{ number of safety accidents and accident rate (\%) by place } \\
\cline { 2 - 13 } & $\begin{array}{c}\text { rocks on the } \\
\text { seashore }\end{array}$ & tideland & $\begin{array}{c}\text { uninhabitable } \\
\text { islands }\end{array}$ & breakwater & port & beach & coast & offshore & bridge & etc. & Total \\
\hline Total & $593(18.1)$ & $267(8.2)$ & $146(4.5)$ & $326(10.0)$ & $738(22.6)$ & $453(13.9)$ & $446(13.6)$ & $187(5.7)$ & $75(2.3)$ & $37(1.1)$ & 3268 \\
\hline 2017 & $146(21.1)$ & $38(5.5)$ & $36(5.2)$ & $90(13.0)$ & $148(21.4)$ & $94(13.6)$ & $83(12.0)$ & $52(7.5)$ & $2(0.3)$ & $4(0.6)$ & 693 \\
2018 & $138(18.3)$ & $55(7.3)$ & $28(3.7)$ & $57(7.6)$ & $187(24.8)$ & $125(16.6)$ & $105(13.9)$ & $46(6.1)$ & $3(0.4)$ & $9(1.2)$ & 753 \\
2019 & $166(17.7)$ & $77(8.2)$ & $46(4.9)$ & $104(11.1)$ & $198(21.2)$ & $118(12.6)$ & $134(14.3)$ & $48(5.1)$ & $31(3.3)$ & $14(1.5)$ & 936 \\
2020 & $143(16.1)$ & $97(10.9)$ & $36(4.1)$ & $75(8.5)$ & $205(23.1)$ & $116(13.1)$ & $124(14.0)$ & $41(4.6)$ & $39(4.4)$ & $10(1.1)$ & 886 \\
\hline
\end{tabular}

(): Ratio of accidents against total (\%) 
유형으로 분석되었다. 제주청(제주도) 관할구역은 해안가, 항 포구, 갯바위에서 익수, 추락에 의한 사고가 주된 사고 유형 으로 분석되었다(Fig. 3, Table 5). 따라서 연안사고를 줄이기 위해서는 이들 장소에 중점을 두고 추락 및 고립 사고를 예 방하기 위한 대비책 마련이 필요할 것으로 판단된다.

연안사고 통계자료의 분석결과를 기반으로 연안활동장소별 해양외력 및 기상여건에 관한 위험요소를 식별하여 다음 Table 6에 제시하였다.

상기 내용을 종합할 경우 연안활동장소의 위험도 평가시에
는 조위 상승속도, 해무 발생여부, 고파랑 등이 주요 외력인 자로 고려되어야 할 것이다. 갯바위, 간출암, 방파제 등 장소 유형별로 높이 및 경사도, 공극률, 조위 상승속도 등 지형적 특성을 반영할 경우 위험도 평가의 실효성을 증진시킬 수 있 으나, 각 장소유형별 특성을 평가하는 절차 및 평가 방법론이 복잡해질 가능성이 높고 1,000 여 개소에 달하는 국내 전체의 위험구역을 대상으로 평가하는 것은 현실적으로 어렵다 판단 된다. 따라서 본 연구에서는 장소유형별 개별특성을 고려하지 않고 공통적인 위협요인을 선정하여 평가시 활용하고자 한다.

Table 6. Hazards of activity place

\begin{tabular}{|c|c|c|c|}
\hline \multicolumn{3}{|c|}{ Classify place } & risk item \\
\hline \multirow{7}{*}{$\begin{array}{l}\text { coastal } \\
\text { experience } \\
\text { activity }\end{array}$} & \multirow{2}{*}{$\begin{array}{l}\text { general } \\
\text { type }\end{array}$} & tideland experience & \multirow{2}{*}{$\begin{array}{l}\text { wave, sea fog, tidal range (tide unawareness), rising velocity of tide level, } \\
\text { wind, rainfall, number of swell }\end{array}$} \\
\hline & & fishing place & \\
\hline & \multirow{3}{*}{$\begin{array}{l}\text { surface } \\
\text { type }\end{array}$} & swimming site & \multirow{3}{*}{$\begin{array}{l}\text { wave, sea fog, tidal range (tide unawareness), rising velocity of tide level, } \\
\text { wind, rainfall, number of swell }\end{array}$} \\
\hline & & boot camp & \\
\hline & & water playground & \\
\hline & \multirow{2}{*}{$\begin{array}{l}\text { underwater } \\
\text { type }\end{array}$} & diving training site & \multirow{2}{*}{ - wave, tide } \\
\hline & & diving experience site & \\
\hline \multirow{6}{*}{\multicolumn{2}{|c|}{ general }} & tideland & $\begin{array}{l}\text { - tidal range (tide unawareness), rising velocity of tide level, number of sea } \\
\text { fog for a year, escape time }\end{array}$ \\
\hline & & rocks on the seashore & $\begin{array}{l}\text { - height and gradient, tidal range (tide unawareness), rising velocity of tide } \\
\text { level, high wave, number of swell, sphagnum }\end{array}$ \\
\hline & & breakwater & - height and gradient, porosity, wave, number of swell, sphagnum \\
\hline & & port & - high wave, number of swell, gradient, sphagnum \\
\hline & & uninhabitable islands & $\begin{array}{l}\text { - tidal range (tide unawareness), rising velocity of tide level, high wave, num- } \\
\text { ber of swell }\end{array}$ \\
\hline & & coast & $\begin{array}{l}\text { - tidal range (tide unawareness), rising velocity of tide level, high wave, num- } \\
\text { ber of swell }\end{array}$ \\
\hline
\end{tabular}

Table 7. Comparison of risk assessment systems

\begin{tabular}{|c|c|c|}
\hline Classification & present & this study \\
\hline assessment base & coast guard instruction No.197 & supplement of coast guard instruction No.197 \\
\hline assessment system & simple index assessment & simple index assessment \\
\hline $\begin{array}{l}\text { assessment func- } \\
\text { tion }\end{array}$ & static & static \\
\hline assessment factor & $\begin{array}{l}\circ \text { accident prevention facility (3score) } \\
\circ \text { information delivery facility }(2 \text { score) } \\
\circ \text { rescue facility ( } 2 \text { score) } \\
\circ \text { time of accident response (2score) } \\
\circ \text { increase or decrease of visitor (1score) }\end{array}$ & $\begin{array}{l}\text { - natural and topographical factors: topography, tide, wave, } \\
\text { weather } \\
\text { - human and accident factors: accident history, death toll } \\
\text { - facilities and management factors: accident prevention. } \\
\text { information delivery rescue facility, response time }\end{array}$ \\
\hline assessment result & $\begin{array}{c}\text { if the score is } 5 \text { or more, it's managed } \\
\text { as s single hazard area. }\end{array}$ & $\begin{array}{l}\text { Risks are classified into grades } \\
1-5 \text { for each zone. }\end{array}$ \\
\hline weight & unapplied & application of AHP analysis \\
\hline assessment cycle & 1 year & 1 year \\
\hline weakness & $\begin{array}{l}\text { - qualitative assessment with strong subjectivity } \\
\text { - can't consider place characteristics }\end{array}$ & $\begin{array}{l}\text { some of the qualitative assessment items with strong } \\
\text { subjectivity are included. }\end{array}$ \\
\hline advantage & - simple assessment and easy procedure & $\begin{array}{l}\text { - consideration of statistics based qualitative assessment } \\
\text { - simple assessment and easy procedure } \\
\text { - considering place characteristics(accident rate by place) }\end{array}$ \\
\hline
\end{tabular}




\section{4. 위험도 평가체계 수립 및 적용}

\section{1 위험도 평가체계 수립}

국내의 지정·관리되고 있는 위험구역들은 해역별로 자연요 소, 기상요소 및 인적요소에 따른 사고 위험정도가 각각 다 르므로 이를 반영할 수 있는 평가지표의 정량화 방안 및 표 준화된 방법론 개발이 필요하다. 현행 평가 체계(해양경찰청 훈령 제197호)의 정성평가 및 장소특성을 고려하지 못하는 한 계를 극복하고 일관된 프로세서를 통해 측정 가능한 지표를 토대로 위험도 평가가 수행될 수 있는 방법론을 수립하였다. 현행 평가체계와 본 연구를 통해 수립된 평가체계를 비교하 여 다음 Table 7에 제시하였다.

본 연구에서는 현행 평가체계와 동일한 지수 기반 평가방
법을 제안하였으며, 위험구역의 지형적 요인에 의한 사고 위 험성, 조석 및 파랑 외력 등 정량적 외력 요인을 추가하여 현 행 평가체계를 보완할 수 있도록 수립하였다. 평가요인으로 는 자연·지형 요인, 인적·사고 요인, 시설·관리 요인 등 3 개로 구성하였으며, 평가요인 및 지표별 가중치는 AHP(Analytic Hierarchy Process) 분석을 통해 고려하였다. 본 연구를 통해 수립된 위험도 평가체계는 다음 Table 8과 같으며, 각 평가 지표의 위험성 산출을 위해 활용되는 통계자료의 출처와 AHP 분석을 통해 산정된 평가지표별 가중치를 함께 제시하였다.

위험도는 9점 척도를 기준으로 1 5등급으로 구분되며, 위험 도는 다음 식(1)과 같이 각 평가요인의 지표별 위험성에 가중 치를 고려한 결과를 합산하여 계산된다. 계산된 위험도는 1 5 등급으로 구분되며, 1 등급인 경우 위험도가 매우 낮음을 의미

Table 8. Risk assessment system of coastal activity areas

\begin{tabular}{|c|c|c|c|c|c|c|}
\hline \multirow{2}{*}{$\begin{array}{l}\text { assessment } \\
\text { factor }\end{array}$} & \multirow{2}{*}{$\begin{array}{l}\text { assessment } \\
\text { index }\end{array}$} & \multirow{2}{*}{ explain index } & \multicolumn{4}{|c|}{ statistical data for product of assessment index } \\
\hline & & & application data & character & application period & source \\
\hline \multirow{4}{*}{$\begin{array}{l}\text { natural and } \\
\text { topographical } \\
\text { factors } \\
(0.205)\end{array}$} & $\begin{array}{l}\text { topography } \\
(0.047)\end{array}$ & accident rate by place & $\begin{array}{l}\text { status of safety } \\
\text { accident }\end{array}$ & variability & $\begin{array}{l}\text { total accumulation } \\
\text { data }(2017 \sim)\end{array}$ & coastal guard \\
\hline & $\begin{array}{l}\text { tide } \\
(0.057)\end{array}$ & rising velocity of tide level & $\begin{array}{l}\text { TideBed and } \\
\text { tidal bench mark }\end{array}$ & fixed & $\begin{array}{l}\text { reflection of } \\
\text { recent results }\end{array}$ & $\begin{array}{c}\text { korea } \\
\text { hydrographic } \\
\text { and } \\
\text { oceanographic } \\
\text { agency }\end{array}$ \\
\hline & $\begin{array}{l}\text { wave } \\
(0.089)\end{array}$ & $\begin{array}{l}\text { prevalence of significant } \\
\text { wave by wave height }\end{array}$ & $\begin{array}{c}\text { wave data result } \\
\text { of long-term } \\
\text { hindcast simulation } \\
\text { in } 2019 \text { Deepwater } \\
\text { Design Wave }\end{array}$ & fixed & $\begin{array}{l}\text { last } 20 \text { years } \\
(2000 \sim 2019)\end{array}$ & $\begin{array}{l}\text { Ministry of } \\
\text { Oceans and } \\
\text { Fisheries }\end{array}$ \\
\hline & $\begin{array}{l}\text { weather } \\
(0.011)\end{array}$ & $\begin{array}{l}\text { occurrence day of sea } \\
\text { fog and wind speed }\end{array}$ & $\begin{array}{l}\text { number of fog day, } \\
\text { average wind speed }\end{array}$ & variability & $\begin{array}{l}\text { 30-year average data } \\
\text { (last } 30 \text { years) }\end{array}$ & $\begin{array}{c}\text { Korea } \\
\text { meteorological } \\
\text { administration }\end{array}$ \\
\hline \multirow{2}{*}{$\begin{array}{l}\text { human and } \\
\text { accident } \\
\text { factors } \\
(0.636)\end{array}$} & $\begin{array}{l}\text { accident } \\
\text { history } \\
(0.217)\end{array}$ & $\begin{array}{c}\text { number of coastal accident } \\
\text { (annual average) }\end{array}$ & $\begin{array}{l}\text { status of safety } \\
\text { accident }\end{array}$ & variability & $\begin{array}{l}\text { total accumulation } \\
\text { data }(2017 \sim)\end{array}$ & \multirow{6}{*}{ coastal guard } \\
\hline & $\begin{array}{l}\text { death toll } \\
(0.419)\end{array}$ & death toll & $\begin{array}{l}\text { status of safety } \\
\text { accident }\end{array}$ & variability & last 3 years & \\
\hline \multirow{4}{*}{$\begin{array}{c}\text { facilities and } \\
\text { management } \\
\text { factors } \\
(0.159)\end{array}$} & $\begin{array}{l}\text { accident } \\
\text { prevention } \\
\text { facility } \\
(0.061)\end{array}$ & $\begin{array}{l}\text { management of accident } \\
\text { prevention facility }\end{array}$ & $\begin{array}{l}\text { report of Risk } \\
\text { investigation }\end{array}$ & variability & $\begin{array}{l}\text { reflection of } \\
\text { recent results }\end{array}$ & \\
\hline & $\begin{array}{l}\text { information } \\
\text { delivery } \\
\text { facility } \\
(0.016)\end{array}$ & $\begin{array}{l}\text { management of information } \\
\text { delivery facility }\end{array}$ & $\begin{array}{l}\text { report of Risk } \\
\text { investigation }\end{array}$ & variability & $\begin{array}{l}\text { reflection of } \\
\text { recent results }\end{array}$ & \\
\hline & $\begin{array}{l}\text { rescue } \\
\text { facility } \\
(0.010)\end{array}$ & $\begin{array}{l}\text { management of } \\
\text { rescue facility }\end{array}$ & $\begin{array}{l}\text { report of Risk } \\
\text { investigation }\end{array}$ & variability & $\begin{array}{l}\text { reflection of } \\
\text { recent results }\end{array}$ & \\
\hline & $\begin{array}{l}\text { time of } \\
\text { accident } \\
\text { response } \\
(0.073)\end{array}$ & $\begin{array}{l}\text { time of accident response } \\
\text { to hazard area }\end{array}$ & $\begin{array}{l}\text { report of Risk } \\
\text { investigation }\end{array}$ & variability & $\begin{array}{l}\text { reflection of } \\
\text { recent results }\end{array}$ & \\
\hline
\end{tabular}

(): Weight using AHP (Analytic Hierarchy Process) 
Table 9. Classification of risk assessment results

\begin{tabular}{ccc}
\hline \hline grade & assessment base & risk grade \\
\hline 1 & risk grade $<1$ & \\
\hline 2 & $1 \leq$ risk grade $<2$ & low \\
& $2 \leq$ risk grade $<4$ & $\uparrow$ \\
& high \\
\hline 4 & $4 \leq$ risk grade $<6$ & \\
\hline 5 & $6 \leq$ risk grade &
\end{tabular}

하고 5 등급의 경우 위험도가 매우 높음을 의미한다(Table 9).

$$
\begin{gathered}
\text { 위험도 }=(\text { 자연·지형요인 위험성 } \times \text { 가중치 }) \\
+(\text { 인적·사고요인 위험성 } \times \text { 가중치 }) \\
+(\text { 시설·관리요인 위험성 } \times \text { 가중치 })
\end{gathered}
$$

\section{2 평가지표별 등급화}

자연·지형 요인, 인적·사고 요인, 시설·관리요인으로 분류된 평가요인별 총 10 개 평가지표에 대하여 각각 9 개 구간으로 개별 위험성을 등급화 하였으며, 다음 Table 10 12에 평가지
표별 등급화 및 평가 척도를 제시하였다.

(1) 자연·지형 요인

자연·지형 요인은 장소 유형별 사고 발생률, 조위상승속도, 파고별 출현율, 연간 해무 발생일수 및 최대풍속 출현율를 산 정하여 등급화 하였다(Table 10). 지형 지표는 각 지방청별로 장소 유형별 사고발생률을 산정하고 이를 계급별로 등급화 하 였으며, 조석 지표는 대조기시 시간당 조위상승속도(평균대조 차(시간)를 계산하여 평가하였다. 이때 조석지표는 갯벌 고립 사고가 빈번하게 발생하는 전라북도 군산 이북 연안의 위험 도가 가장 높게 평가되도록 설정하였다. 파랑 지표는 위험구 역 인근에서 취득할 수 있는 파랑자료의 유의파고 값과 계급 별 출현율을 고려하여 평가하였다. 기상 지표의 경우 기상청 에서 운영 중인 위험구역 인근 기상대의 안개 발생일수 및 풍 속자료를 활용하며, 평년값을 기준으로 하되 30년 미만인 지 역은 전체 관측기간 자료를 활용하여 산정하게 된다.

(2) 인적·사고 요인

인적·사고 요인은 연평균 사고발생 건수 및 사망자 수를 정

\begin{tabular}{|c|c|c|c|c|c|c|}
\hline \multirow{3}{*}{ grade } & \multicolumn{5}{|c|}{ grade criteria } & \multirow{3}{*}{$\begin{array}{l}\text { risk } \\
\text { grade }\end{array}$} \\
\hline & \multirow{2}{*}{$\begin{array}{c}\text { topography } \\
\text { (accident rate, } \\
\% \text { ) }\end{array}$} & \multirow{2}{*}{$\begin{array}{c}\text { tide } \\
\text { (rising velocity, } \\
\mathrm{cm} / \mathrm{hr} \text { ) }\end{array}$} & \multirow{2}{*}{$\begin{array}{c}\text { wave } \\
\text { (average of significant } \\
\text { wave, } \mathrm{m} \text { ) }\end{array}$} & \multicolumn{2}{|c|}{ weather } & \\
\hline & & & & sea fog (day) & wind speed $(\mathrm{m} / \mathrm{s})$ & \\
\hline 1 & $x<3$ & $x<10$ & $x<0.25$ & $x<10$ & $x<2.175$ & \multirow{9}{*}{$\begin{array}{c}\text { low } \\
\uparrow\end{array}$} \\
\hline 2 & $3 \leq x<6$ & $10 \leq x<20$ & $0.25 \leq x<0.50$ & $10 \leq x<20$ & $2.175 \leq x<3.850$ & \\
\hline 3 & $6 \leq x<9$ & $20 \leq x<30$ & $0.50 \leq x<0.75$ & $20 \leq x<30$ & $3.850 \leq x<5.525$ & \\
\hline 4 & $9 \leq x<12$ & $30 \leq x<40$ & $0.75 \leq x<1.00$ & $30 \leq x<40$ & $5.525 \leq x<7.200$ & \\
\hline 5 & $12 \leq x<15$ & $40 \leq x<50$ & $1.00 \leq x<1.25$ & $40 \leq x<50$ & $7.200 \leq x<8.875$ & \\
\hline 6 & $15 \leq x<18$ & $50 \leq x<60$ & $1.25 \leq x<1.50$ & $50 \leq x<60$ & $8.875 \leq x<10.550$ & \\
\hline 7 & $18 \leq x<21$ & $60 \leq x<80$ & $1.50 \leq x<1.75$ & $60 \leq x<70$ & $10.550 \leq x<12.225$ & \\
\hline 8 & $21 \leq x<24$ & $80 \leq x<95$ & $1.75 \leq x<2.00$ & $70 \leq x<80$ & $12.225 \leq x<13.900$ & \\
\hline 9 & $x \geq 24$ & $x \geq 95$ & $x \geq 2.00$ & $x \geq 80$ & $x \geq 13.900$ & \\
\hline
\end{tabular}
규화하여 지표로 활용하게 된다(Table 11). 사고이력 지표는

Table 10. Risk grade of natural and topography factors

\begin{tabular}{|c|c|c|c|}
\hline \multirow{2}{*}{ grade } & \multicolumn{2}{|c|}{ grade criteria } & \multirow{2}{*}{$\begin{array}{l}\text { risk } \\
\text { grade }\end{array}$} \\
\hline & accident history & death toll & \\
\hline 1 & number of coastal safety accident $\leq 1$ & 1 person & \\
\hline 3 & $x \leq 2$ & & low \\
\hline 5 & $x \leq 3$ & 2 people & $\uparrow$ \\
\hline 7 & $x \leq 4$ & & high \\
\hline 9 & $x \geq 5$ & $x \geq 3$ people & \\
\hline
\end{tabular}

Table 11. Risk grade of human and accident factors

\begin{tabular}{|c|c|c|c|c|c|}
\hline \multirow{2}{*}{ grade } & \multicolumn{4}{|c|}{ grade criteria } & \multirow{2}{*}{$\begin{array}{c}\text { risk } \\
\text { grade }\end{array}$} \\
\hline & accident prevention facility & information delivery facility & rescue facility & time of accident response & \\
\hline 0 & appropriate & appropriate & appropriate & & \\
\hline 1 & & & & $x<10$ minutes & low \\
\hline 3 & need to replace & need to replace & need to replace & 10 minutes $\leq x<20$ minutes & $\uparrow$ \\
\hline 6 & lack & lack & lack & 20 minutes $\leq x<30$ minutes & hioh \\
\hline 9 & not installed & not installed & not installed & $x \geq 30$ minutes & \\
\hline
\end{tabular}

Table 12. Risk grade of safety facilities and management factors 
전체 누적기간의 연간 안전사고 발생건수를 평균하여 등급화 하게 되며, 사망자 수 지표의 경우 위험구역내 최근 3년간 사 망자 수를 평가하여 등급화 하였다.

\section{(3) 시설·관리 요인}

시설·관리 요인은 사고예방시설, 정보전달시설, 구난시설, 사 고 대응시간 총 4 개 평가지표로 구성되며, 연안사고 안전관 리규정에 따라 해양경찰청이 매년 실시하는 위험성 평가 결 과를 활용하게 된다(Table 12). 사고예방시설, 정보전달시설, 구난시설 지표는 해양경찰청의 위험성 평가결과에서 제시한 각 시설물의 적정·보수교체 필요.부족.미설치로 통일된 분류 기준에 따라 등급화 하였으며, 이때 시설물이 적정한 경우 사 고발생 위험성이 제거되었다고 판단하여 0 등급을 부여하게 된 다. 사고 대응시간 지표는 연안사고 발생시 구조를 위해 해
당 파출소에서 위험구역까지 이동하는데 소요되는 시간을 산 정하여 등급화 하였다.

\section{3 평가지표별 등급화}

앞서 수립된 연안활동장소에 대한 위험도 평가체계를 해양 경찰청에서 관리되고 있는 위험구역 중 사고발생률이 높은 40 개소를 대상으로 적용하였다. 위험구역별 평가지표의 위험도 등급은 다음 Table 13에 제시하였으며, 가중치를 고려한 위 험도 평가결과는 Table 14에 제시하였다.

40 개소 주요 위험구역의 위험도는 2 등급 이상으로, 2 등급 이 11 개소, 3 등급 25 개소, 4 등급 3 개소, 5 등급 1 개소로 평가 되었다. 사고발생률 및 사망률이 높은 중부청 관할 위험구역 의 위험도가 타 지방청에 비해 높게 평가되고 있으며, 중부

Table 13. Risk grade of evaluation index at hazard area

\begin{tabular}{|c|c|c|c|c|c|c|c|c|c|c|c|}
\hline \multirow[b]{2}{*}{ Classification } & \multirow[b]{2}{*}{ hazard area } & \multicolumn{4}{|c|}{ natural and topographical factors } & \multicolumn{2}{|c|}{$\begin{array}{l}\text { human and } \\
\text { accident factors }\end{array}$} & \multicolumn{4}{|c|}{ facilities and management factors } \\
\hline & & topography & tide & wave & weather & $\begin{array}{c}\text { number of } \\
\text { accident }\end{array}$ & $\begin{array}{c}\text { death } \\
\text { toll }\end{array}$ & $\begin{array}{l}\text { accident } \\
\text { prevention } \\
\text { facility }\end{array}$ & $\begin{array}{c}\text { information } \\
\text { delivery } \\
\text { facility }\end{array}$ & $\begin{array}{l}\text { rescue } \\
\text { facility }\end{array}$ & $\begin{array}{l}\text { time of } \\
\text { accident } \\
\text { response }\end{array}$ \\
\hline \multirow{11}{*}{ Central } & Eurwangni Beach & 4 & 9 & 3 & 5 & 9 & 5 & 9 & 0 & 3 & 3 \\
\hline & Eurwangni Wharf & 5 & 9 & 3 & 5 & 1 & 5 & 6 & 6 & 6 & 3 \\
\hline & Wangsan Beach & 4 & 9 & 3 & 5 & 3 & 1 & 9 & 0 & 0 & 3 \\
\hline & Seonyeo Rock & 9 & 9 & 3 & 5 & 5 & 1 & 9 & 6 & 9 & 3 \\
\hline & Wolmido & 4 & 9 & 3 & 5 & 7 & 5 & 9 & 6 & 6 & 6 \\
\hline & Jebudo Beach & 4 & 9 & 3 & 5 & 1 & 1 & 9 & 6 & 0 & 3 \\
\hline & Maebawi Rock & 9 & 9 & 3 & 5 & 3 & 9 & 6 & 3 & 6 & 3 \\
\hline & Bangpo Beach & 4 & 9 & 3 & 5 & 1 & 1 & 9 & 3 & 6 & 6 \\
\hline & Bangpo Port & 5 & 9 & 3 & 5 & 1 & 1 & 9 & 6 & 6 & 9 \\
\hline & Halmibawi and Harabibawi & 9 & 9 & 3 & 5 & 1 & 1 & 9 & 6 & 9 & 6 \\
\hline & Seondori Tidal Flat & 8 & 9 & 3 & 5 & 3 & 1 & 3 & 3 & 6 & 3 \\
\hline \multirow{5}{*}{ West } & Bieung Port Breakwater & 3 & 8 & 3 & 5 & 1 & 1 & 0 & 0 & 0 & 1 \\
\hline & Chaeseokgang Cliff & 6 & 8 & 3 & 5 & 5 & 1 & 9 & 3 & 9 & 1 \\
\hline & Dongmyeong Port & 9 & 6 & 3 & 4 & 3 & 1 & 0 & 3 & 3 & 1 \\
\hline & Wando Port Breakwater & 3 & 5 & 3 & 3 & 1 & 5 & 6 & 6 & 3 & 1 \\
\hline & Gukdong Port & 9 & 5 & 3 & 2 & 3 & 1 & 0 & 3 & 0 & 1 \\
\hline \multirow{8}{*}{ East } & Sokcho Port (North) & 9 & 1 & 3 & 3 & 1 & 1 & 3 & 6 & 3 & 1 \\
\hline & Jumunjin Port (North) & 9 & 1 & 3 & 2 & 1 & 1 & 6 & 6 & 6 & 1 \\
\hline & Jumunjin Port & 5 & 1 & 3 & 2 & 1 & 1 & 6 & 6 & 6 & 1 \\
\hline & Gallam Beach Rock & 3 & 1 & 4 & 2 & 1 & 1 & 6 & 6 & 6 & 1 \\
\hline & Chuksan Port (North) & 9 & 1 & 4 & 4 & 1 & 1 & 6 & 6 & 9 & 1 \\
\hline & Odolri Rock & 3 & 1 & 4 & 1 & 1 & 1 & 6 & 6 & 6 & 3 \\
\hline & Guryongpo Port & 5 & 1 & 4 & 1 & 1 & 1 & 0 & 9 & 9 & 1 \\
\hline & Guryongpo Port Breakwater & 9 & 1 & 4 & 1 & 1 & 1 & 9 & 6 & 6 & 1 \\
\hline \multirow{7}{*}{ South } & Ilsan Beach & 6 & 1 & 4 & 1 & 1 & 1 & 6 & 3 & 3 & 1 \\
\hline & Bangeojin Port & 4 & 1 & 3 & 1 & 5 & 1 & 6 & 6 & 9 & 1 \\
\hline & World-Cup Breakwater & 4 & 2 & 4 & 1 & 1 & 1 & 6 & 6 & 6 & 1 \\
\hline & Millak Port Breakwater & 4 & 2 & 3 & 2 & 1 & 1 & 0 & 0 & 6 & 1 \\
\hline & Igidae Rock & 4 & 2 & 3 & 2 & 1 & 1 & 3 & 3 & 6 & 6 \\
\hline & Samcheonpo New-Port & 9 & 5 & 3 & 2 & 1 & 1 & 6 & 9 & 9 & 1 \\
\hline & Hakdong Beach & 4 & 3 & 4 & 1 & 1 & 1 & 0 & 0 & 0 & 9 \\
\hline \multirow{9}{*}{ Jeju } & Hamdeok Beach & 6 & 3 & 3 & 1 & 1 & 1 & 6 & 3 & 3 & 9 \\
\hline & Sehwa-pogu & 7 & 3 & 4 & 2 & 1 & 1 & 3 & 0 & 6 & 9 \\
\hline & Wimi Port Breakwater & 3 & 4 & 3 & 2 & 1 & 1 & 3 & 6 & 3 & 6 \\
\hline & Hwasungeum Beach & 7 & 4 & 4 & 3 & 1 & 1 & 9 & 6 & 6 & 1 \\
\hline & Hwasun Port Breakwater & 3 & 4 & 4 & 3 & 1 & 1 & 9 & 6 & 9 & 1 \\
\hline & Hwasun Port & 7 & 4 & 4 & 3 & 1 & 1 & 3 & 9 & 6 & 1 \\
\hline & Hallim Shipowner-Accoc. Dock & 7 & 4 & 4 & 3 & 1 & 1 & 9 & 6 & 6 & 1 \\
\hline & Hallim Outer-Port Breakwater & 3 & 4 & 4 & 4 & 1 & 1 & 6 & 6 & 3 & 1 \\
\hline & Hallim-shipyard Breakwater & 3 & 4 & 4 & 4 & 1 & 1 & 9 & 6 & 9 & 1 \\
\hline
\end{tabular}


Table 14. Results of risk assessment

\begin{tabular}{|c|c|c|c|c|c|c|c|c|c|c|c|c|c|}
\hline \multirow{2}{*}{ Classification } & \multirow{2}{*}{ hazard area } & \multicolumn{4}{|c|}{ natural and topographical factors } & \multicolumn{4}{|c|}{ human and accident factors } & \multicolumn{2}{|c|}{$\begin{array}{l}\text { facilities and } \\
\text { management } \\
\text { factors }\end{array}$} & \multirow{2}{*}{ Total } & \multirow{2}{*}{$\begin{array}{l}\text { risk } \\
\text { grade }\end{array}$} \\
\hline & & topography & tide & wave & weather & $\begin{array}{c}\text { number } \\
\text { of } \\
\text { accident }\end{array}$ & $\begin{array}{c}\text { death } \\
\text { toll }\end{array}$ & $\begin{array}{l}\text { accident } \\
\text { prevention } \\
\text { facility }\end{array}$ & $\begin{array}{c}\text { information } \\
\text { delivery } \\
\text { facility }\end{array}$ & $\begin{array}{l}\text { rescue } \\
\text { facility }\end{array}$ & $\begin{array}{l}\text { time of } \\
\text { accident } \\
\text { response }\end{array}$ & & \\
\hline \multirow{11}{*}{ Central } & Eurwangni Beach & 0.188 & 0.513 & 0.286 & 0.055 & 1.953 & 2.095 & 0.549 & 0.000 & 0.030 & 0.219 & 5.888 & 4 \\
\hline & Eurwangni Wharf & 0.235 & 0.513 & 0.286 & 0.055 & 0.217 & 2.095 & 0.366 & 0.096 & 0.060 & 0.219 & 4.142 & 4 \\
\hline & Wangsan Beach & 0.188 & 0.513 & 0.286 & 0.055 & 0.651 & 0.419 & 0.549 & 0.000 & 0.000 & 0.219 & 2.880 & 3 \\
\hline & Seonyeo Rock & 0.423 & 0.513 & 0.286 & 0.055 & 1.085 & 0.419 & 0.549 & 0.096 & 0.090 & 0.219 & 3.735 & 3 \\
\hline & Wolmido & 0.188 & 0.513 & 0.286 & 0.055 & 1.519 & 2.095 & 0.549 & 0.096 & 0.060 & 0.438 & 5.799 & 4 \\
\hline & Jebudo Beach & 0.188 & 0.513 & 0.286 & 0.055 & 0.217 & 0.419 & 0.549 & 0.096 & 0.000 & 0.219 & 2.542 & 3 \\
\hline & Maebawi Rock & 0.423 & 0.513 & 0.286 & 0.055 & 0.651 & 3.771 & 0.366 & 0.048 & 0.060 & 0.219 & 6.392 & 5 \\
\hline & Bangpo Beach & 0.188 & 0.513 & 0.313 & 0.055 & 0.217 & 0.419 & 0.549 & 0.048 & 0.060 & 0.438 & 2.800 & 3 \\
\hline & Bangpo Port & 0.235 & 0.513 & 0.313 & 0.055 & 0.217 & 0.419 & 0.549 & 0.096 & 0.060 & 0.657 & 3.114 & 3 \\
\hline & Halmibawi and Harabibawi & 0.423 & 0.513 & 0.313 & 0.055 & 0.217 & 0.419 & 0.549 & 0.096 & 0.090 & 0.438 & 3.113 & 3 \\
\hline & Seondori Tidal Flat & 0.376 & 0.513 & 0.323 & 0.055 & 0.651 & 0.419 & 0.183 & 0.048 & 0.060 & 0.219 & 2.847 & 3 \\
\hline \multirow{5}{*}{ West } & Bieung Port Breakwater & 0.141 & 0.456 & 0.323 & 0.055 & 0.217 & 0.419 & 0.000 & 0.000 & 0.000 & 0.073 & 1.684 & 2 \\
\hline & Chaeseokgang Cliff & 0.282 & 0.456 & 0.326 & 0.055 & 1.085 & 0.419 & 0.549 & 0.048 & 0.090 & 0.073 & 3.383 & 3 \\
\hline & Dongmyeong Port & 0.423 & 0.342 & 0.343 & 0.044 & 0.651 & 0.419 & 0.000 & 0.048 & 0.030 & 0.073 & 2.373 & 3 \\
\hline & Wando Port Breakwater & 0.141 & 0.285 & 0.332 & 0.033 & 0.217 & 2.095 & 0.366 & 0.096 & 0.030 & 0.073 & 3.668 & 3 \\
\hline & Gukdong Port & 0.423 & 0.285 & 0.280 & 0.022 & 0.651 & 0.419 & 0.000 & 0.048 & 0.000 & 0.073 & 2.201 & 3 \\
\hline \multirow{8}{*}{ East } & Sokcho Port (North) & 0.423 & 0.057 & 0.347 & 0.033 & 0.217 & 0.419 & 0.183 & 0.096 & 0.030 & 0.073 & 1.878 & 2 \\
\hline & Jumunjin Port (North) & 0.423 & 0.057 & 0.350 & 0.022 & 0.217 & 0.419 & 0.366 & 0.096 & 0.060 & 0.073 & 2.083 & 3 \\
\hline & Jumunjin Port & 0.235 & 0.057 & 0.350 & 0.022 & 0.217 & 0.419 & 0.366 & 0.096 & 0.060 & 0.073 & 1.895 & 2 \\
\hline & Gallam Beach Rock & 0.141 & 0.057 & 0.367 & 0.022 & 0.217 & 0.419 & 0.366 & 0.096 & 0.060 & 0.073 & 1.818 & 2 \\
\hline & Chuksan Port (North) & 0.423 & 0.057 & 0.394 & 0.044 & 0.217 & 0.419 & 0.366 & 0.096 & 0.090 & 0.073 & 2.179 & 3 \\
\hline & Odolri Rock & 0.141 & 0.057 & 0.393 & 0.011 & 0.217 & 0.419 & 0.366 & 0.096 & 0.060 & 0.219 & 1.979 & 2 \\
\hline & Guryongpo Port & 0.235 & 0.057 & 0.381 & 0.011 & 0.217 & 0.419 & 0.000 & 0.144 & 0.090 & 0.073 & 1.627 & 2 \\
\hline & Guryongpo Port Breakwater & 0.423 & 0.057 & 0.381 & 0.011 & 0.217 & 0.419 & 0.549 & 0.096 & 0.060 & 0.073 & 2.286 & 3 \\
\hline \multirow{7}{*}{ South } & Ilsan Beach & 0.282 & 0.057 & 0.378 & 0.011 & 0.217 & 0.419 & 0.366 & 0.048 & 0.030 & 0.073 & 1.881 & 2 \\
\hline & Bangeojin Port & 0.188 & 0.057 & 0.334 & 0.011 & 1.085 & 0.419 & 0.366 & 0.096 & 0.090 & 0.073 & 2.719 & 3 \\
\hline & World-Cup Breakwater & 0.188 & 0.114 & 0.363 & 0.011 & 0.217 & 0.419 & 0.366 & 0.096 & 0.060 & 0.073 & 1.907 & 2 \\
\hline & Millak Port Breakwater & 0.188 & 0.114 & 0.306 & 0.022 & 0.217 & 0.419 & 0.000 & 0.000 & 0.060 & 0.073 & 1.399 & 2 \\
\hline & Igidae Rock & 0.188 & 0.114 & 0.306 & 0.022 & 0.217 & 0.419 & 0.183 & 0.048 & 0.060 & 0.438 & 1.995 & 2 \\
\hline & Samcheonpo New-Port & 0.423 & 0.285 & 0.297 & 0.022 & 0.217 & 0.419 & 0.366 & 0.144 & 0.090 & 0.073 & 2.336 & 3 \\
\hline & Hakdong Beach & 0.188 & 0.171 & 0.375 & 0.011 & 0.217 & 0.419 & 0.000 & 0.000 & 0.000 & 0.657 & 2.038 & 3 \\
\hline \multirow{9}{*}{ Jeju } & Hamdeok Beach & 0.282 & 0.171 & 0.349 & 0.011 & 0.217 & 0.419 & 0.366 & 0.048 & 0.030 & 0.657 & 2.550 & 3 \\
\hline & Sehwa-pogu & 0.329 & 0.171 & 0.386 & 0.022 & 0.217 & 0.419 & 0.183 & 0.000 & 0.060 & 0.657 & 2.444 & 3 \\
\hline & Wimi Port Breakwater & 0.141 & 0.228 & 0.316 & 0.022 & 0.217 & 0.419 & 0.183 & 0.096 & 0.030 & 0.438 & 2.090 & 3 \\
\hline & Hwasungeum Beach & 0.329 & 0.228 & 0.380 & 0.033 & 0.217 & 0.419 & 0.549 & 0.096 & 0.060 & 0.073 & 2.384 & 3 \\
\hline & Hwasun Port Breakwater & 0.141 & 0.228 & 0.380 & 0.033 & 0.217 & 0.419 & 0.549 & 0.096 & 0.090 & 0.073 & 2.226 & 3 \\
\hline & Hwasun Port & 0.329 & 0.228 & 0.380 & 0.033 & 0.217 & 0.419 & 0.183 & 0.144 & 0.060 & 0.073 & 2.066 & 3 \\
\hline & Hallim Shipowner-Accoc. Dock & 0.329 & 0.228 & 0.368 & 0.033 & 0.217 & 0.419 & 0.549 & 0.096 & 0.060 & 0.073 & 2.372 & 3 \\
\hline & Hallim Outer-Port Breakwater & 0.141 & 0.228 & 0.368 & 0.044 & 0.217 & 0.419 & 0.366 & 0.096 & 0.030 & 0.073 & 1.982 & 2 \\
\hline & Hallim-shipyard Breakwater & 0.141 & 0.228 & 0.368 & 0.044 & 0.217 & 0.419 & 0.549 & 0.096 & 0.090 & 0.073 & 2.225 & 3 \\
\hline
\end{tabular}

청을 제외한 지방청별 위험도는 2 3등급 범위로 평가되었다. 위험도가 높은 지역으로는 제부도 남측의 매바위 인근이 5 등 급으로 가장 높은 것으로 평가되었고, 을왕해수욕장 및 을왕 선착장, 월미도 지역의 위험도는 4등급으로 평가되었다.

\section{5. 결 론}

본 연구에서는 해양경찰청에서 관리하고 있는 연안활동장 소의 위험도 평가를 위한 위험성 평가지표 설정 및 평가 방 법론을 제안하고 각 지방청별로 지정.관리되고 있는 40 개 위 험구역을 대상으로 수립된 방법을 적용하였다. 연안활동장소 의 위험도 평가방법은 평가인자의 산정등급을 집계하여 표현 하는 지수 기반 평가방법을 기반으로 수립하였으며, 자연.지
형 요인, 인적·사고 요인, 시설·관리 요인 등 3 개 평가지표에 총 10 개의 평가인자를 구성하고 인자별 가중치를 고려하여 총 5 개 등급의 위험도로 표출하는 방안을 제시하였다.

본 연구를 통해 제안된 위험도 평가방법은 현행 해양경찰 청에서 운영하고 있는 위험도 평가방법의 정성적이고 주관성 이 강한 취약점을 보완하였으며, 위험구역의 지형적 특성의 고려가 가능할 뿐 아니라 해양경찰청이 자체적으로 취합하고 있는 연안안전사고 통계자료와 연안사고 안전관리규정(해양 경찰청훈령 제197호)에 따라 매년 지방청별로 실시되는 위험 성 조사결과를 활용하여 해양경찰청에서 간편하게 위험도 등급을 산정할 수 있는 방법론을 제공하는데 의미를 두고자 한다.

향후 각 분야 전문가 의견수렴을 통해 지속적으로 지표 및 
가중치의 보완과 국내 관리되고 있는 전체 위험구역을 대상 으로 확장적용하여 현장적용성을 평가할 필요가 있으며, 아 울러 국제기준을 만족하면서 효율적 위험평가가 가능한 리스 크 기반 위험성 평가체계도 함께 검토함으로써 지표의 표준 화 문제, 가중치 문제, 중요지표 문제 등을 종합적으로 해소 할 수 있는 방안을 마련할 계획이다.

\section{감사의 글}

이 논문은 2021년 해양경찰청 재원으로 해양수산과학기술 진흥원의 지원을 받아 수행된 연구임(20200527 연안활동장 소에 대한 위험도 평가 및 예측 체계 개발).

\section{References}

Carvalho, R.C. and Woodroffe, C.D. (2019). Morphological Exposure of Rocky Platforms: Filling the Hazard Gap Using UAVs. Drones 2019, 3, 42.

Kim, D.S. (2019). Study on improvement of coastal safety management system to prevent coastal water accident. The Journal of the Korean Public Security Administration, 16(1), 3-28 (in Korean).

Korea Coast Guard (2018). Coastal Safety and Risk Quantification Study to Prepare Indicators for Coastal Risk Assessment (in
Korean).

Lee, Y.J., Jung, C.Y. and Gu, J.Y. (2020). Development of risk rating and index for coastal activity locations. Journal of the Korean Society of Marine Environment \& Safety, 26(3), 227232.

Ministry of Ocean and Fisheries (2017). A Study on the Introduction of Coastal Safety Index (in Korean).

Ministry of Ocean and Fisheries (2019). A Study on the Introduction of Coastal Safety Index (in Korean).

MPSS (Ministry of Public Safety and Security) Marine Security Headquarters (2016). A Study on Efficient Coastal Safety Management for Prevention of Coastal Safety Accidents (in Korean).

Satta, A., Venturini, S., Puddu, M., Firth, J. and Lafitte, A. (2015). Application of a Multi-Scale Coastal Risk Index at Regional and Local Scale in the Mediterranean. Technical Report.

Song, C.Y. (2019). A Study on the improvement of safety management for coastal accidents in Korea. Journal of the Korea Institute for Structural Maintenance and Inspection, 23(7), 95103 (in Korean).

Tweed Shire Council (2018). Coastal Public Safety Risk Assessment Main Report-Risk Assessment and Treatment Plan 2018 Fingal Head.

Received 12 November, 2021

Accepted 30 November, 2021 